\title{
edificio Creole
}

LATHROP DUGLASS, arquitecto

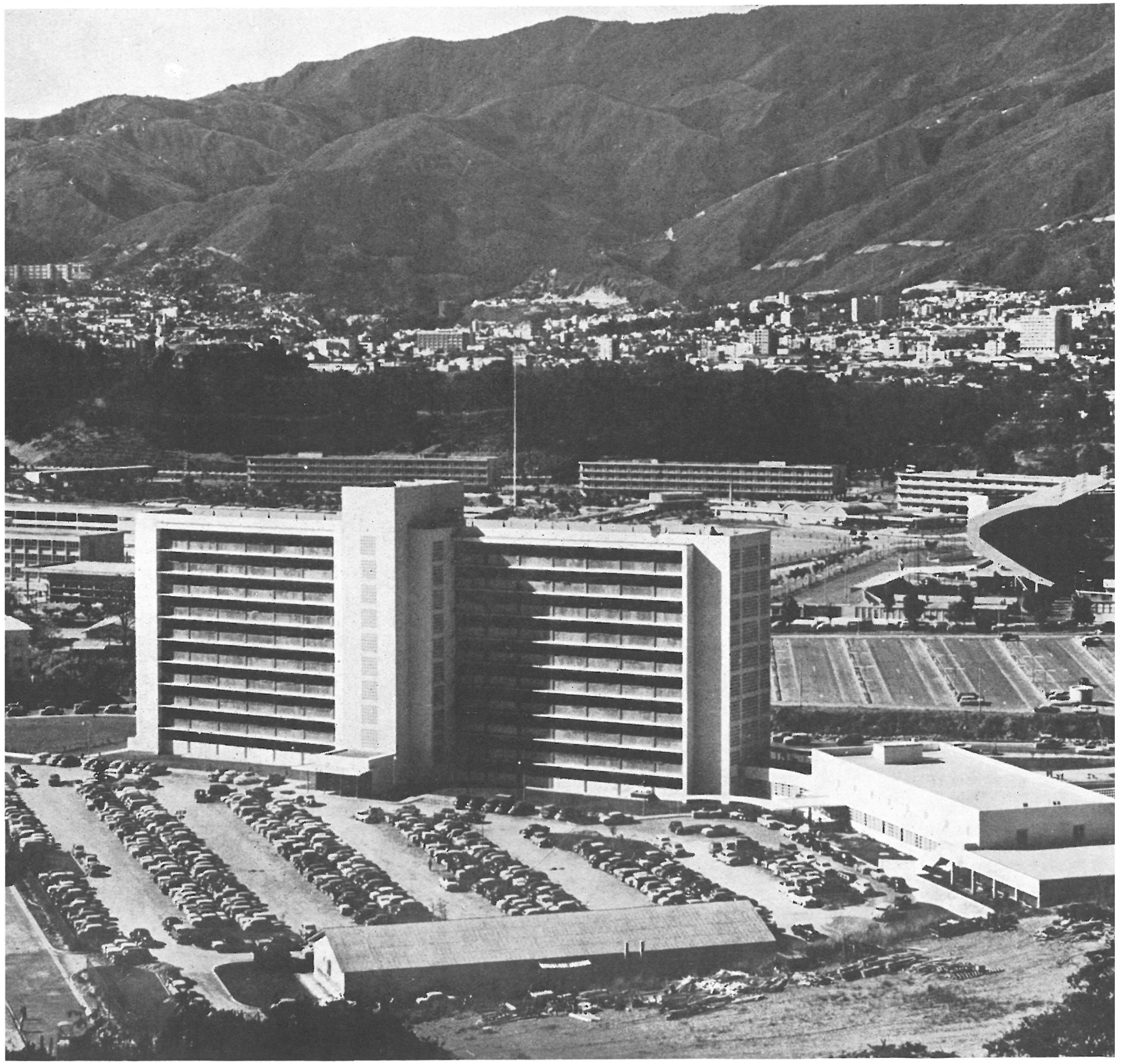

En la Caracas actual, una de las ciudades más modernas del mundo, donde se levantan soberbios edificios de avanzadas líneas, se ha construído éste, siguiendo las directrices simplistas y de funcionalismo, características y propias de nuestra época.

El total de la construcción consta de dos bloques: uno de diez plantas y sótano, destinado para oficinas, con estructura de acero y modulación flexible, y otro de dos plantas, también con sótano, que se dedica para funciones más específicas, estructurado con hormigón. Se prevé un amplio espacio para aparcamiento (200 coches).

La orientación axial es Este-Oeste, con la zona de oficinas al Norte y al Sur y un pasillo central. Esta disposi ción proporciona una agradable comunicación con la naturaleza agreste y soberbia de las montañas del fondo. 


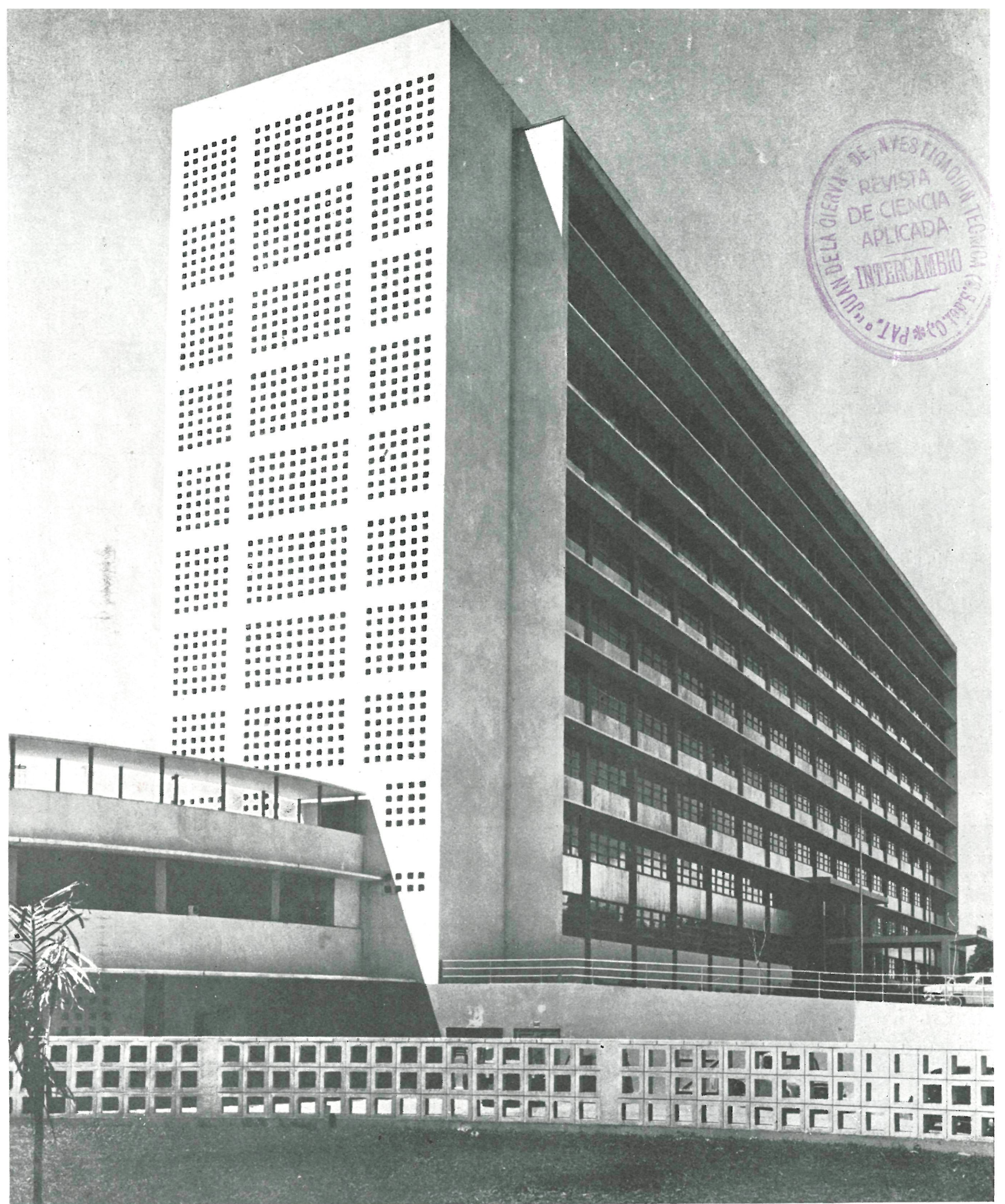

Para lograr la necesaria protección del sol, se colocan viseras de hormigón en las fachadas Norte y Sur. Las escaleras y los servicios reciben la luz y el calor solar, por medio de unas celosías reticuladas en los piñones terminales del edificio y en el cuerpo saliente central. La ventilación es a base de ventiladores eléctricos, por haberlo considerado más económico que un sistema mecánico.

Debido a la posibilidad de tener que resistir efrctos sísmicos se cambió la estructura inicial, en la que se habian dispuesto soportes solamente en el exterior, por la actual, consistente en tres filas paralelas de soportes, que definen claramente dos crujías de anchura distinta $(5,8$ y $8,8 \mathrm{~m})$. 


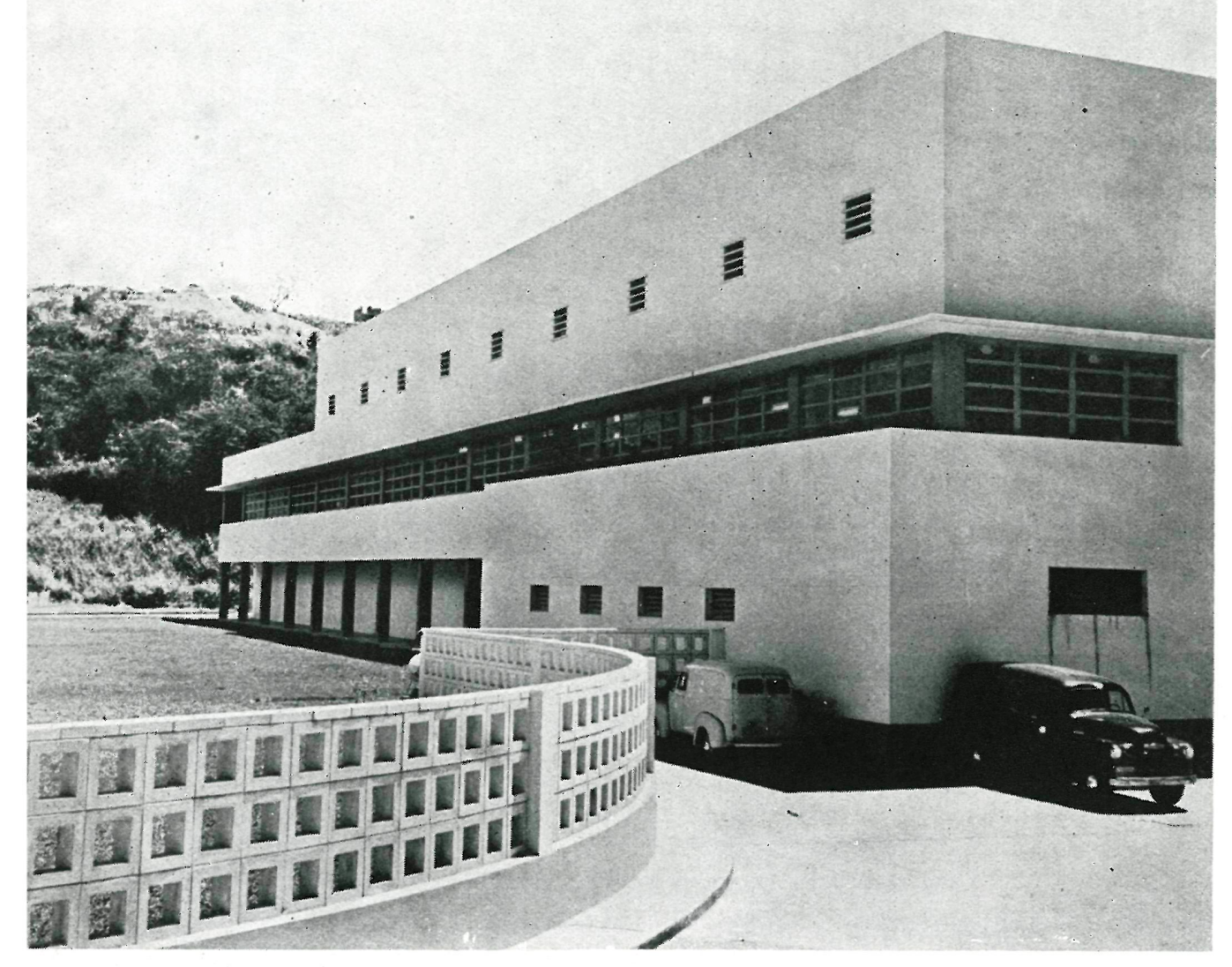

Bloque de tres plantas. Fachada Noreste.

Fachada N. y puerta principal.
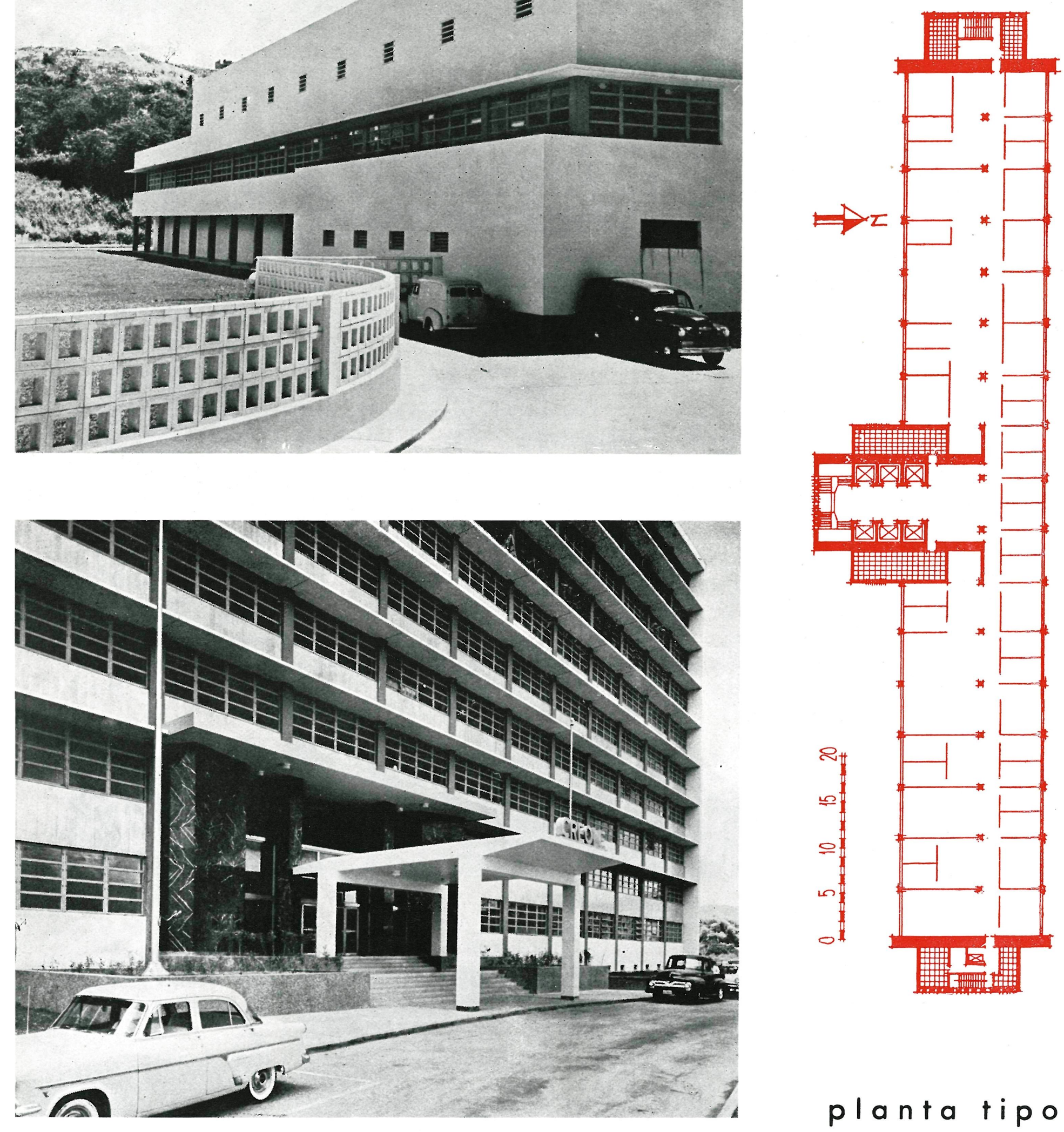


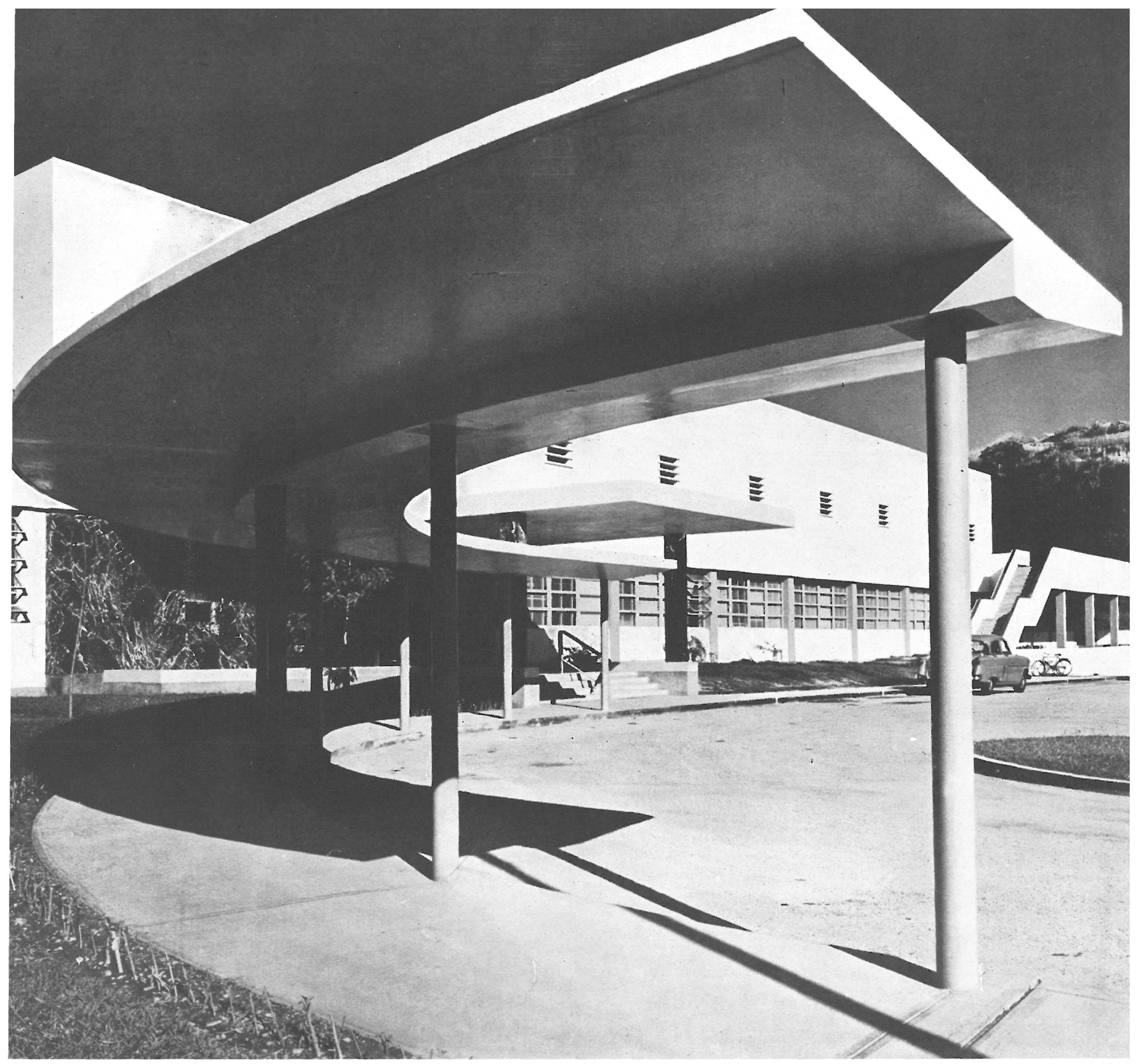

Los muros terminales y los del cuerpo saliente central, fuertes y resistentes, tienen la finalidad de estabilizar el bloque principal, estrecho y largo, contra los efectos sísmicos.

La construcción general es de acero, con lo que se consigue una mayor flexibilidad y diafanidad, con pilares y arriostramientos de este material, cerrando las enjutas con chapas de aluminio, en los antepechos de los huecos.

Los techos y suelos son celulares y de acero, lo que permite mayor facilidad en la colocación de conductos eléctricos. Los tabiques son también metálicos y responden a una modulación.

La unión entre ambos bloques se hace por medio de un cuerpo constructivo, que comprende las dos plantas del bloque pequeño: la inferior, completamente cerrada, y la superior, cubierta con una placa curva.
Las partes de fachada que no están cerradas por chapas de aluminio-en los antepechos de las ventanas-y las propias ventanas acristaladas, se han estucado con polvo de mármol, lo cual da un aspecto de piedra muy agradable, sólido y duradero, sin necesidad de pintura.

La expansión necesaria para los empleados, se ha previsto con la construcción de un espacio romboidal, dedicado al baseball y otros deportes.

En todo el edificio, que en líneas generales tiene el aspecto de otros tantos productos de la arquitectura contemporánea, ha regido la norma de solucionar práctica, económica y rápidamente todos los problemas, sin concesiones arbitrarias a la apariencia, que no estén previamente justificadas. Ha resultado asi una construcción de proporciones gratas y gran diafanidad, perfectamente acoplada, en el lugar elegido, con los edificios circundantes, tales como la Universidad.

V. M. 


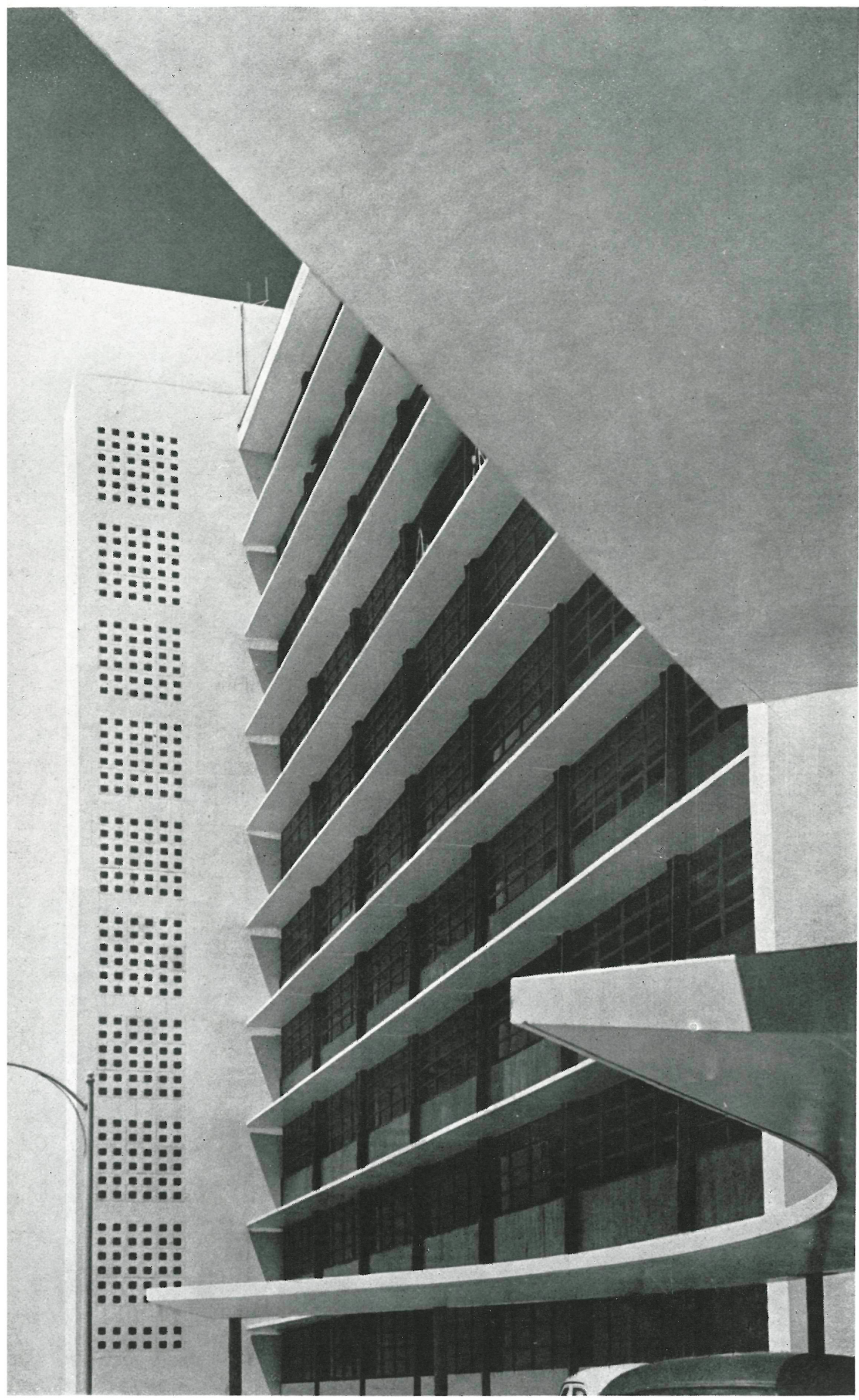

oficina

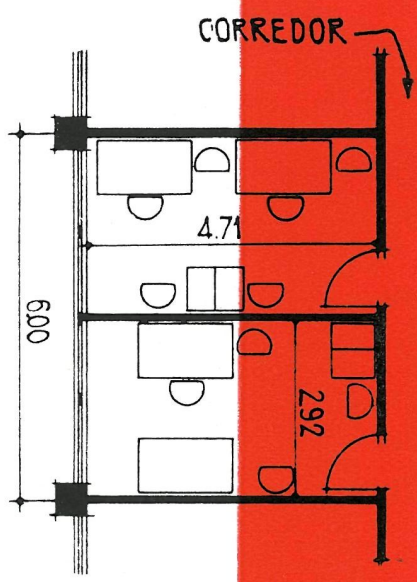

detalle de cerramien

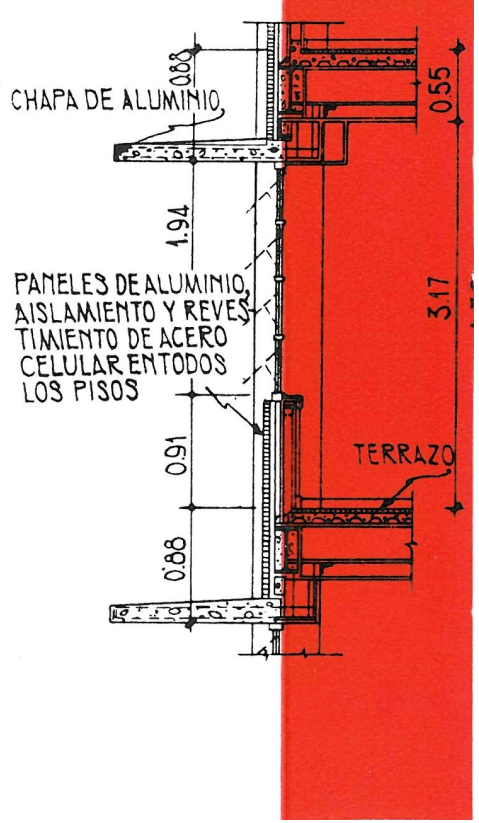

